\title{
EVALUATION OF SPATIAL JUSTICE IN ACCESSIBILITY OF URBAN FACILITIES: A CASE STUDY OF ACCESSIBILITY OF PUBLIC PARKS IN DISTRICT \# 11 OF TEHRAN, IRAN
}

\author{
S. Mahmoudi ${ }^{1}$, M.R. Jelokhani-Niaraki ${ }^{1}{ }^{*}$, M. Argany ${ }^{1}$ \\ ${ }^{1}$ Department of GIS and Remote Sensing, Faculty of Geography, University of Tehran, Iran - somaye.mahmoudi@ut.ac.ir, \\ mrjelokhani@ut.ac.ir-argany@ut.ac.ir
}

KEY WORDS: Spatial justice, Accessibility, GIS, Urban facilities, Public park, Spatial indicator

\begin{abstract}
:
The green spaces and urban parks play a critical role to improve the quality of life of citizens. In order to meet the principles of the justice-based city and spatial justice in the distribution of public services, it is necessary to evaluate the accessibility to parks in different locations and pay more attention to the places with a low level of accessibility. This study evaluates the spatial justice or inequalities in accessibility to urban parks in District \# 11 of Tehran, Iran using a set of spatial indices and GIS tools. Indices used in this study are Covering, Minimum distance, Average distance, Proximity, Two-step floating catchment area and Gravity-based twostep floating catchment area. The results indicate that the level of accessibility to mini and neighborhood parks are almost similar and below the average level. The slight differences in the results are related to the differences in the assumptions and logics of methods. Moreover, the results show that the Coverage, 2SFCA and GB2SFCA (with inappropriate distance decay coefficient) methods face limitations when the accessibility for the community parks are calculated. For example, the Coverage method does not take into account the area of the park for measuring the accessibility level, in turn, this leads to inaccurate results. Overall, the findings show better accessibility to community parks than mini and neighborhood parks. This implies that the municipalities need to increase the number of local mini and neighborhood parks across the city.
\end{abstract}

\section{INTRODUCTION}

Public parks are one of the essential urban amenities for communities and neighborhoods. They provide a number of benefits, such as healthy lifestyles, recreational facilities, the clean air and water, and age- and family-friendly places (Chiesura et al, 2004, Smith et al, 2013, Van Kamp et al, 2003, Yang et al, 2005, Boone, 2009, Jo, 2002). The positive impact of proximity and accessibility to public parks on human health, including reduced mortality rates, cardiovascular disease, diabetes and obesity has been proven (Gordon-Larsen, 2006). The spatial distribution of parks in cities is usually unbalanced, and this imbalance and spatial disparity in accessibility to parks are considered as a serious problem in urban areas (Wolch et al, 2013). In recent years, a particular attention has been paid to the fair distribution of urban parks and green spaces in developed and developing cities (Lee et al, 2013, Yao et al, 2014, You, 2016). Previous studies have provided several methods or indicators for estimating the level of accessibility to public parks, including Covering, Thiessen polygon, Minimum distance, Average distance, Simple distance indicator, Proximity indicator, Two step floating catchment area, Gravitybased two-step floating catchment area, Enhanced two-step floating catchment area, and Variable-width floating catchment area. Although new methods have been developed or improvements of existing methods have been made to estimate the levels of accessibility to urban facilities such as parks (for example: Daniele La Rosa, 2013, Lee et al, 2013, Meng et al, 2015, Dony et al, 2015, Xing et al, 2018, Xio et al, 2018), none of the studies have compared these methods. In this study, the level of accessibility to urban parks in District \# 11 of Tehran have been calculated using the set of spatial indicators and then the results are compared. Contrary to previous studies which use a simple Euclidean distance approach to compute the indices, this study utilizes a network-based distance approach in order to achieve more realistic results.

\section{METHODOLOGY}

\subsection{Study area}

Tehran is the fastest growing city in Iran. It is divided into 22 municipal districts, each with its own administrative center, as there is a shortage of public parks, open spaces and green areas in the city, the inequality in accessibility of public parks to local residents has emerged as an area of serious concern. District \# 11 of Tehran, Iran was selected as the study area. Spatial distribution of population density and parks in the study area is shown in Fig. 1. The accessibility of public parks in District \# 11 was investigated using the spatial indicators mentioned earlier.

\subsection{Data and Data pre-processing}

In this study, the data used to calculate the spatial indices are as follows: 1) The street layer, which was converted to the network layer of the streets in order to calculate network-based distance;

\footnotetext{
* Corresponding author
} 
2) The population layer of the district with units at the level of the block, and 3) The layer of the parks.

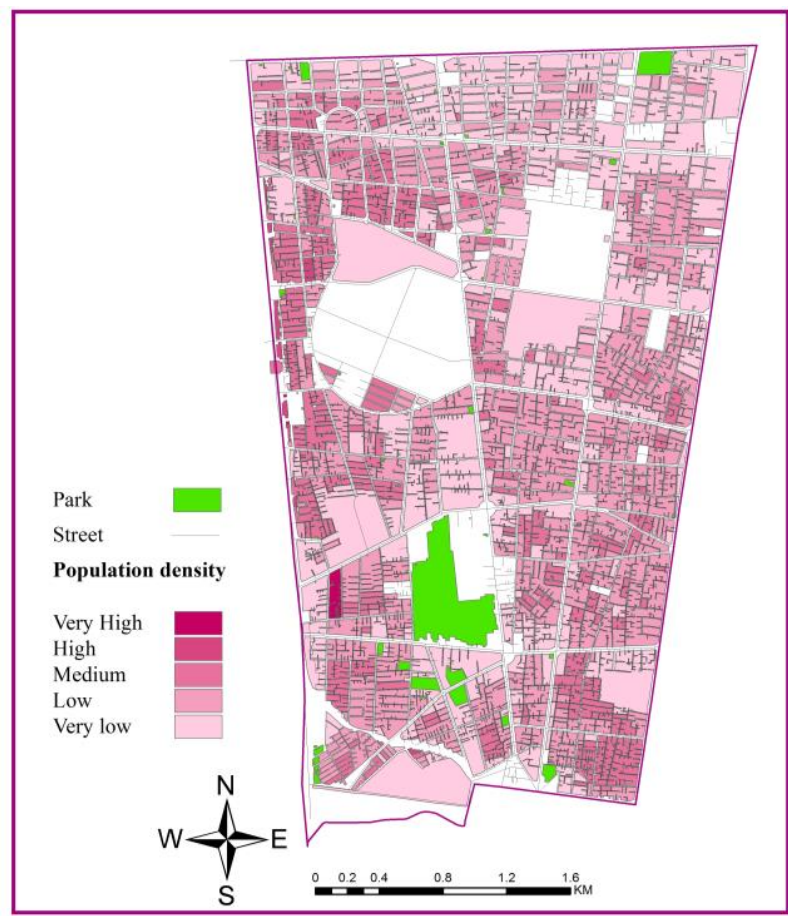

Figure 1. Spatial distribution of population density and public parks in the study area

Data pre-processing consists of a four stages procedure: The first stage involves the classification of the parks into three groups according to their area, including mini parks with an area of less than one acre, neighborhood parks with an area between one to twenty acres and community parks with an area between 20 up to 50 acres (Mertes et al, 1995). The reason for the classification is that different types of public parks, such as mini, neighborhood, and community parks, have different sizes of service areas (Meng et al, 2015). Table 1 shows the classification of parks and the assignment of their respective service area. The second stage is to extract the centroids of the park polygons and population blocks. The third and fourth steps involve the use of spatial analysis tools to build a network topology based on the street layer and fix the errors, respectively.

\begin{tabular}{|l|l|l|}
\hline Type of park & \multicolumn{1}{|c|}{ Location criteria } & \multicolumn{1}{|c|}{ Site criteria } \\
\hline Mini Park & $\begin{array}{l}\text { Service area usually } \\
\text { less than } 0.4 \mathrm{~km}\end{array}$ & $\begin{array}{l}\text { Usually less than } \\
1 \text { acre }\end{array}$ \\
\hline $\begin{array}{l}\text { Neighborhood } \\
\text { Park }\end{array}$ & $\begin{array}{l}\text { Service area usually } \\
\text { no more than } 0.8 \mathrm{~km}\end{array}$ & $\begin{array}{l}\text { Minimum of } 1 \\
\text { acres, maximum } \\
20 \text { acres }\end{array}$ \\
\hline $\begin{array}{l}\text { Community } \\
\text { Park }\end{array}$ & $\begin{array}{l}\text { Service area usually } \\
\text { serves 4.83 km }\end{array}$ & $\begin{array}{l}\text { Between 20 and } \\
50 \text { acres }\end{array}$ \\
\hline $\begin{array}{l}\text { Table 1. Public park and open space classification scheme } \\
\text { (Mertes et al, 1995) Note: With a little change proportional } \\
\text { to the study area }\end{array}$ \\
\hline
\end{tabular}

\subsection{Calculation of accessibility indicators}

2.3.1 Covering method: In this method, first, three zones are generated around the centroid of each population block based on the service area of mini, neighborhood and community parks (see Table 1), and then the number of parks that are within these service areas is determined. Finally, the ratio of the number of parks to the block population can be calculated according to Equation 1 (Meng et al, 2015).

$$
\mathrm{A}_{\mathrm{j}}=\frac{N}{\mathrm{P}_{\mathrm{j}}}
$$

$$
\begin{array}{ll}
\text { where } & A_{j}=\text { accessibility of } j_{\text {th }} \text { population block } \\
& N=\text { total number of } i_{\text {th park within service area }} \\
& P_{j}=\text { population of } j_{\text {th }} \text { block }
\end{array}
$$

2.3.2 Minimum distance method: Similar to the covering method, three zones are generated around the centroid of each population block based on the service areas (see Table 1). Next, the distance between the population block and the nearest park within the service area is calculated. Finally, the distance is weighted according to the population of the block using Equation 2 (Meng et al, 2015).

$$
\mathrm{A}_{j}=D \times \mathrm{P}_{\mathrm{j}}
$$

where $\quad A_{j}=$ accessibility of $j_{\text {th }}$ population block

$\mathrm{D}=$ distance from $\mathrm{i}$ th nearest park from the $\mathrm{j}$ th block $\mathrm{P}_{\mathrm{j}}=$ population of $\mathrm{j}_{\mathrm{th}}$ block

2.3.3 Average distance method: Similar to the method mentioned above, three zones are generated around the centroid of each population block based on the service areas (see Table 1 ), and then the mean of the distances between the population block and all of the parks within the service area is calculated. Finally, the mean value of the distances was weighted according to the population of the block using Equation 3 (Meng et al, 2015).

$$
\mathrm{A}_{\mathrm{j}}=\frac{\sum_{i \epsilon S} d_{i j}}{\mathrm{~N}} \times \mathrm{P}_{\mathrm{j}}
$$

where $\quad A_{j}=$ accessibility of $j_{t h}$ population block

$\mathrm{d}_{\mathrm{ij}}=$ distance from $\mathrm{i}_{\text {th }}$ park from the $\mathrm{j}$ - block

$P_{j}=$ population of $j$ th block

$\mathrm{N}=$ total number of $\mathrm{i}_{\text {th }}$ park within service area

2.3.4 Proximity method: In this method, first service areas around each of population blocks is determined, then the area of each park within the service area of the population block is weighted according to their distance to the block, and finally, according to equation 4 are aggregated (Daniele La Rosa, 2013).

$$
\operatorname{Prox}_{i}=\sum_{j=1}^{n} \frac{\text { Park }_{j}}{\text { Dist }_{j i}^{2}}
$$

where $\quad$ Prox $_{i}=$ proximity indicator for $i_{\text {th block }}$ Park $_{\mathrm{j}}=$ area of $\mathrm{jth}_{\text {th }}$ park 
block

Dist $\mathrm{j}_{\mathrm{i}}=$ distance between $\mathrm{j}_{\mathrm{th}}$ park and $\mathrm{i}_{\text {th }}$ population

2.3.5 Two step floating catchment area (2SFCA): This method involves two steps: 1) Determining the population within the service area of each park in order to calculate the supply-demand ratio of the park according to Equation 5 (Xiaokun et al, 2017).

$$
R_{j}=\frac{S_{j}}{\sum_{i \in\left(d_{i j} \leq d_{0}\right)} P_{i}}
$$

where $\quad R_{j}=$ supply to demand ration of $j_{\text {th }}$ park

$S_{j}=$ area of $j$ th park

$\mathrm{P}_{\mathrm{i}}=$ population of $\mathrm{i}_{\mathrm{th}}$ block

$\mathrm{d}_{0}=$ size of service area

$\mathrm{d}_{\mathrm{ij}}=$ distance between $\mathrm{j}_{\mathrm{th}}$ park and $\mathrm{i}_{\mathrm{th}}$ population block

2) Calculating the total supply-demand ratio for parks that fall within the service area around each population block according to Equation 6 (Xiaokun et al, 2017).

$$
\text { Accessibilty }_{\mathrm{i}}=\sum_{\mathrm{j} \epsilon\left(\mathrm{d}_{\mathrm{ij}} \leq \mathrm{d}_{0}\right)} \mathrm{R}_{\mathrm{j}}=\sum_{\mathrm{j} \epsilon\left(\mathrm{d}_{\mathrm{ij}} \leq \mathrm{d}_{0}\right)} \frac{\mathrm{s}_{\mathrm{j}}}{\sum_{\mathrm{i} \epsilon\left(\mathrm{d}_{\mathrm{ij}} \leq \mathrm{d}_{0}\right)} \mathrm{P}_{\mathrm{i}}}
$$

2.3.6 Gravity based two-step floating catchment area (GB2SFCA): In this method, the steps are the same as the 2SFCA method, and only, one distance decay coefficient is incorporated into the model:

$$
R_{j}=\frac{S_{j}}{\sum_{i \in\left(d_{i j} \leq d_{0}\right)} P_{i} w_{d_{i j}}}
$$

$$
\text { Accessibilty }_{i}=\sum_{j \epsilon\left(d_{i j} \leq d_{0}\right)} R_{j} W_{i j}=\sum_{j \epsilon\left(d_{i j} \leq d_{0}\right)} \frac{s_{j}}{\sum_{i \in\left(d_{i j} \leq d_{0}\right)} P_{i} w_{d_{i j}}}
$$

$W_{i j}=\frac{1}{d_{i j}^{\beta}}$

where $\beta=$ distance decay coefficient

In most studies, $\beta$ is determined experimentally (Zhang et al, 2011). In an empirical study by Giles-Corti and Donovan (2002), the value of 1.91 was obtained for this parameter by distributing the questionnaire among the public green space users and performing regression analysis. In the present study, various values of $0.5,1,1.5,1.8$ and 2 were considered for $\beta$ coefficient and the results of applying these values were compared.

\section{RESULTS}

In order to compare the levels of accessibility to each of the mini, neighbourhood and community parks, these values are normalized and converted to values between zero and one. Figure 2 shows the maps representing the accessibility levels obtained based on the six methods. It should be noted that due to the large number of output maps, only the maps resulted from averaging the accessibilities of mini, neighbourhood and community parks are presented. Details of the results of each method are shown in Table 2.

As can be seen from Figure 2 and Table 2, the results of all the methods confirm that the level of accessibility to the mini parks is below average (i.e. low and very low). It should be noted that the results of these methods confirm each other and there is no significant difference between them. In addition, the results of the coverage methods, the minimum distance and the average distance, are closer together because of the lack of consideration of the area of parks in estimating accessibility. On the other hand, the value estimated by the 2SFCA method is more similar to the average distance method than the GB2SFCA method and this is due to the lack of consideration of the distance. The accessibility values obtained by the proximity method are smaller than the results of other methods and most blocks are assigned low or very low access values due to the lack of consideration of the block population. As the results show, the higher the $\beta$ value in the GB2SFCA method, it is assumed that people are less preferred to travel longer distances to reach the park. It should be noted that this method takes into account the area of the parks, the population of the blocks, and the distance between the parks and the population blocks, so it has a more complete logic than other methods but determining the appropriate value for the $\beta$ coefficient is the most important challenge of this method.

The level of accessibility to the Neighbourhood parks is also below average. The slight differences in the results of mentioned methods for accessibility values to the mini and neighbourhood parks are related to the differences in their assumptions and logics. For example, the lack of consideration of the area of parks in coverage, minimum distance and average distance methods, or the population of blocks in the proximity method and the distance in the 2SFCA and GB2SFCA methods. However, the problem of overestimation in the minimum distance, average distance, and the 2SFCA methods or underestimation in the proximity method (caused by the aforementioned reasons) cannot ignored. But there are conflicts in the results regarding the estimation of the level of accessibility to community parks that will be discussed in the following. It is worth noting that there is only one community park in the study area. The reason for the nearly twice the difference between the coverage and the minimum distance methods (see Table 2) here than the estimated accessibility values for mini and neighbourhood parks is that the coverage method is only based on counting the number of parks within the service area (albeit with consideration of block population). Since there is only one community park in the study area, thus the block population plays a key role in differentiating accessibility. But the values obtained from the minimum distance method are both influenced by the population of the blocks and by the proximity or distance of the community park (i.e. the criterion of distance from the park in addition to the population of the blocks). Thus, high accessibility values are allocated to blocks located around the community park that are less distance from the marginal blocks of the park and only $36.2 \%$ of the blocks are estimated to be below average level of accessibility. Another issue that has made a significant difference is the results of the 2SFCA method, which allocates less than average accessibility to only $0.36 \%$ of the blocks. The reason for this can be attributed to the influence of the large area of the community park in the study area. Because the coverage and the minimum distance methods do not take into account the area of the park, and on the other hand the 2SFCA method does not consider the impact of the distance criterion. In fact, in the results of 2SFCA method, the impact of area of the community park has been so great that it has practically affected the population impact, which is one of the limitations of this method. According to the results, it is clear that this has happened even in the GB2SFCA with a $\beta=0.5$ which indicates that the weight of 0.5 is not the appropriate weight for this 
Coline C. Dony, Eric M. Delmelle, Elizabeth C. Delmelle., 2015. Re-conceptualizing accessibility to parks in multi-modal cities: A Variable-width Floating Catchment Area (VFCA) method. Landscape and Urban Planning 143, 90-99.

Daniele La Rosa., 2013. Accessibility to green spaces: GIS based indicators for sustainable planning in a dense urban context. Ecological Indicators vol. 1742.

Giles-Corti, B., \& Donovan, R. J., 2002. The relative influence of individual, social and physical environment determinants of physical activity. Social Science \& Medicine, 54, 1793-1.

Gordon-Larsen, P., Nelson, M., Page, P., \& Popkin, B., 2006. Inequality in the built environment underlies key health disparities in physical activity and obesity. Pediatrics, vol. 117, no. 2, pp. 417-424.

Jo, H.K., 2002. Impacts of urban green space on offsetting carbon emissions for middle Korean. Journal of Environmental Management 64, 115-126.

Lee, G., \& Hong, I., 2013. Measuring spatial accessibility in the context of spatial disparity between demand and supply of urban park service. Landscape and Urban Planning, 119, 8590 .

Lijun Xing., Yanfang Liua., Xingjian Liu., 2018. Measuring spatial disparity in accessibility with a multi-mode method based on park green spaces classification in Wuhan, China. Applied Geography, vol94, pp. 251-261.

Mertes, JD \& Hall, JR, 1995. Park, Recreation, Open Space and Greenway Guidelines, National Recreation and Park Association, Arlington.

Smith, L. M., Case, J. L., Smith, H. M., Harwell, L. C., \& Summers, J. K., 2013. Relating ecosystem services to domains of human well-being: Foundation for a U.S. index. Ecological Indicators, 28, 79-90.

Van Kamp, I., Leidelmeijer, K., Marsman, G., \& de Hollander, A., 2003. Urban environmental quality and human well-being., Landscape and Urban Planning, 65(1-2), 5-18.

Wolch, J., Wilson, J. P., \& Fehrenbach, J., 2013. Parks and park funding in Los Angeles: An equity-mapping analysis. Urban Geography, 26(1), 4-35.

Xiao Xiao, Lisa Aultman-Hallc, Robert Manningd, Brian Voigtd, 2018. The impact of spatial accessibility and perceived barriers on visitation to the US national park system. Journal of Transport Geography 68, 205 -214.

Xiaokun Gu, Siyuan Tao, Bing Dai., 2017. Spatial Accessibility of Country Parks in Shanghai, China. Urban Forestry and Urban Greening.

Yang, J., McBride, J., Zhou, J., Sun, Z., 2005. The urban forest in Beijing and its role in air pollution reduction. , Urban Forestry \& Urban Greening 3, 65-78.
Yao, L., Liu, J., Wang, R., Yin, K., \& Han, B., 2014. Effective green equivalent - a measure of public green spaces for cities. Ecological Indicators, 47, 123-127.

You, H., 2016. Characterizing the inequalities in urban public green space provision in Shenzhen, China. Habitat International, 56, 176-180.

Yunliang Meng, Jacek Malczewski., 2015. A GIS-based multicriteria decision making approach for evaluating accessibility to public parks in Calgary,Alberta. Human Geographies. Vol. 9. 1843-6587.

Zhang, X., Lu, H., \& Holt, J. B., 2011. Modeling spatial accessibility to parks: A national study. International Journal of Health Geographics, 10(31). 